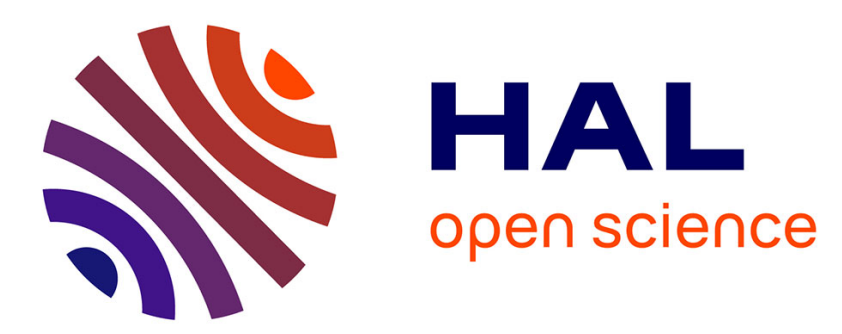

\title{
Opportunities of deoxyribonucleic acid complexes composites for nonlinear optical applications
}

Bouchta Sahraoui, Mindaugas Pranaitis, Denis Gindre, Jacek Niziol, Vaidotas Kažukauskas

\section{- To cite this version:}

Bouchta Sahraoui, Mindaugas Pranaitis, Denis Gindre, Jacek Niziol, Vaidotas Kažukauskas. Opportunities of deoxyribonucleic acid complexes composites for nonlinear optical applications. Journal of Applied Physics, 2011, 110 (8), Non spécifié. 10.1063/1.3655985 . hal-03344700

\section{HAL Id: hal-03344700 \\ https://univ-angers.hal.science/hal-03344700}

Submitted on 15 Sep 2021

HAL is a multi-disciplinary open access archive for the deposit and dissemination of scientific research documents, whether they are published or not. The documents may come from teaching and research institutions in France or abroad, or from public or private research centers.
L'archive ouverte pluridisciplinaire HAL, est destinée au dépôt et à la diffusion de documents scientifiques de niveau recherche, publiés ou non, émanant des établissements d'enseignement et de recherche français ou étrangers, des laboratoires publics ou privés. 


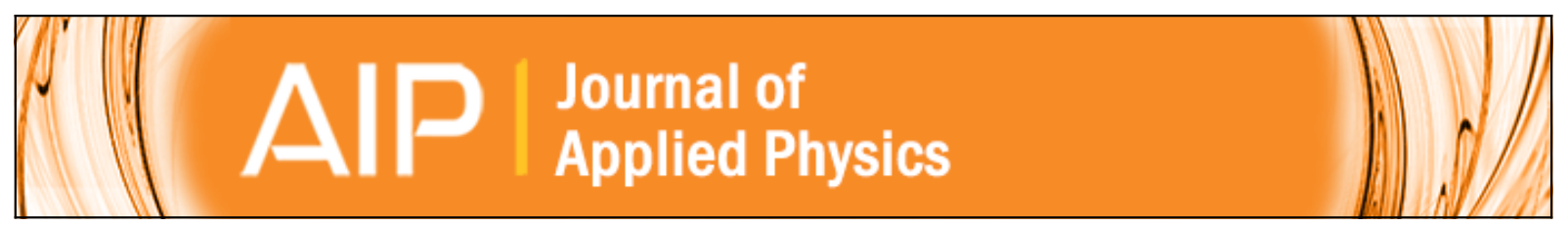

\section{Opportunities of deoxyribonucleic acid complexes composites for nonlinear optical applications}

B. Sahraoui, M. Pranaitis, D. Gindre, J. Niziol, and V. Kažukauskas

Citation: Journal of Applied Physics 110, 083117 (2011); doi: 10.1063/1.3655985

View online: http://dx.doi.org/10.1063/1.3655985

View Table of Contents: http://scitation.aip.org/content/aip/journal/jap/110/8?ver=pdfcov

Published by the AIP Publishing

\section{Articles you may be interested in}

Enhancement of linear and nonlinear optical properties of deoxyribonucleic acid-silica thin films doped with rhodamine

Appl. Phys. Lett. 99, 243304 (2011); 10.1063/1.3669406

Effect of deoxyribonucleic acid on nonlinear optical properties of Rhodamine 6G-polyvinyl alcohol solution J. Appl. Phys. 109, 023110 (2011); 10.1063/1.3520657

Dose effects in electron beam irradiation of DNA-complex thin films

Appl. Phys. Lett. 97, 063702 (2010); 10.1063/1.3478227

Deoxyribonucleic acid-based photochromic material for fast dynamic holography

Appl. Phys. Lett. 91, 041118 (2007); 10.1063/1.2760169

Processing techniques for deoxyribonucleic acid: Biopolymer for photonics applications

Appl. Phys. Lett. 87, 211115 (2005); 10.1063/1.2135205

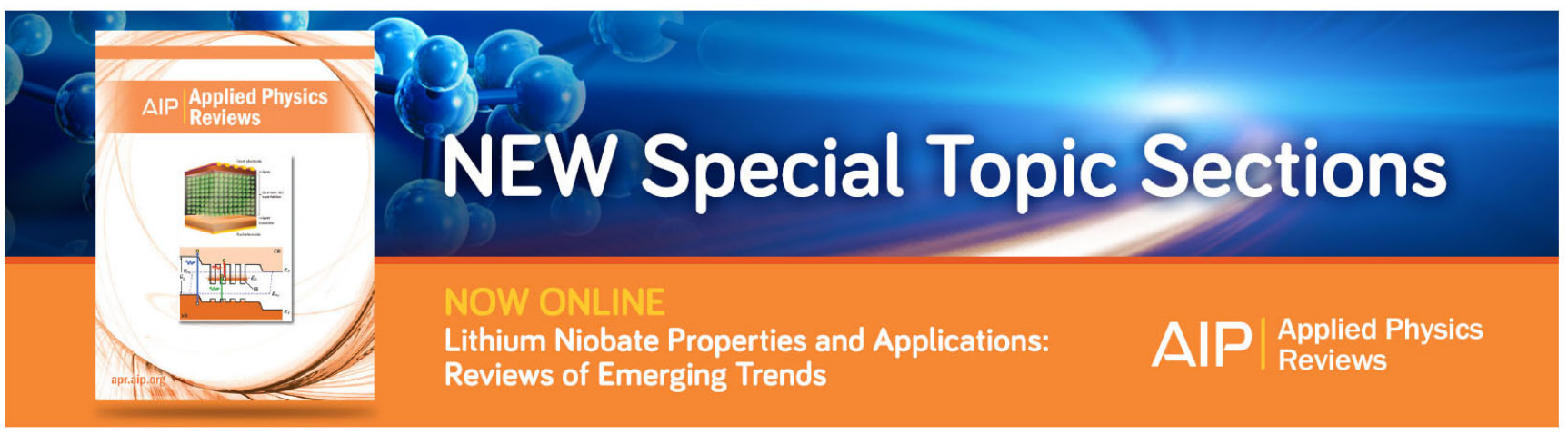




\title{
Opportunities of deoxyribonucleic acid complexes composites for nonlinear optical applications
}

\author{
B. Sahraoui, ${ }^{1, a)}$ M. Pranaitis, ${ }^{1,3}$ D. Gindre, ${ }^{1}$ J. Niziol, ${ }^{2}$ and V. Kažukauskas ${ }^{3}$ \\ ${ }^{1}$ MOLTECH ANJOU, University of Angers, CNRS UMR 6200, F-49045 Angers, France \\ ${ }^{2}$ Faculty of Physics and Applied Computer Science, AGH - University of Science and Technology, \\ al. Mickiewicza 30, 30-059 Krakow, Poland \\ ${ }^{3}$ Department of Semiconductor Physics and Institute of Applied Research of Vilnius University, \\ Sauletekio al. 9, Bld. 3, LT-10222 Vilnius, Lithuania
}

(Received 13 June 2011; accepted 24 August 2011; published online 28 October 2011)

\begin{abstract}
In this paper, we illustrate new functionalities for nonlinear optical applications of bio-molecular systems. This study presents DNA complex with new ionic surfactants. These surfactants enabled DNA solubility in solvents other than alcohols, like aromatic and chlorinated ones. Composites with two nonlinear optical (NLO) active dyes are subjects of the second and third harmonic generation experiments. The found effective nonlinear susceptibilities values are much higher than that for standard fused silica. We also demonstrate any influence of the surfactant on NLO properties. (C) 2011 American Institute of Physics. [doi:10.1063/1.3655985]
\end{abstract}

\section{INTRODUCTION}

Characteristics of bio-derived materials are often inaccessible to man-made polymers. They are obtained from renewable resources, often food industry by-products and, therefore, are biodegradable. Among natural polymers, the leading position is occupied by deoxyribonucleic acid (DNA), the polymer responsible for transfer of genetic code. DNA is a long, thin, organic polymer, the rare macromolecule that represents the atomic scale in width (c.a. $2.37 \mathrm{~nm}$ ) and the human scale in length (a molecule of DNA can be many centimeters long). Although nucleotides (DNA building blocks) may be quite different, all DNA molecules have the same regular structure. ${ }^{1}$ DNA chains can be precisely copied through replication-a natural process, running in living cells. The replication provides mono-dispersed molecular mass of a bulk DNA sample-a feature inexistent among artificial polymers.

The crude DNA, extracted from a natural tissue, is soluble exclusively in water, what practically excludes the standard thin film processing through the spin-coating technique. In addition, DNA is very sensitive to hydration ${ }^{2}$ what makes it highly instable in ambient environment. A breakthrough in DNA-based technology was made by demonstrating series of DNA-cationic surfactant complexes obtained by ion exchange reaction. ${ }^{3}$ The smart choice of cationic surfactants enhanced mechanical resistance of DNA complexes and made it insoluble in water but in revenge soluble in a range of common alcohols.

DNA and its complexes are materials of low optical losses comparable or even lower than that of PMMA, ${ }^{4}$ what is required for a matrix material in composites with optically active molecules. The best quality films were obtained from DNA complex with cetyltrimethylammonium ${ }^{5,6}$ (CTMA) Figure 1(a). Therefore for the last decade, this complex has been considered as a flagship of DNA-based materials for

\footnotetext{
a) Author to whom correspondence should be addressed. Electronic mail: bouchta.sahraoui@univ-angers.fr.
}

application in photonics and molecular electronics. Such applications include: devices based on second and third order nonlinear optical effects, ${ }^{7-9}$ low loss optical waveguides, ${ }^{10}$ information storage, ${ }^{11}$ organic photovoltaic, ${ }^{12}$ and organic field effect transistors. ${ }^{13}$

Despite the success of DNA-CTMA, there is still need for new cationic surfactants which would extend the range of available solvents for DNA complex. In this paper, tests of two such candidates-benzalkonium chloride (BA), Figure 1(b), and didecyldimethylammonium chloride (DDCA), Figure 1(c),- - are described.

The surfactant molecule attaches its cationic head to negatively charged phosphate groups of DNA strand. In the case of CTMA, aliphatic queue is supposed to stretch out. This queue hampers solubility in water and enhances it in other solvents. Following such reasoning BA and DDCA possessing twice as much queues as CTMA does would improve the solubility of DNA in the less polar solvents, including aromatic and chlorinated solvents. The last ones are the most used for dissolving optically active molecular dyes like for example DR1.

The purpose of our work was to verify whether the nature of the surfactant may influence the overall nonlinear optical (NLO) properties of a composite material consisting of DNA complex and a NLO active dye.

\section{EXPERIMENTAL}

\section{A. Sample preparation}

DNA complexes were prepared according to the procedure adapted from Wang et al. $^{3}$ It was found that both complexes regarding the solubility were superior over classical DNA-CTMA. Composites of DNA complexes and original push-pull dyes, belonging to azo-carbazole family were prepared by co-solution in dimethylformamide (DMF), common solvent for both constituents. The detailed synthetic routine of such compounds has been described in Ref. 14 


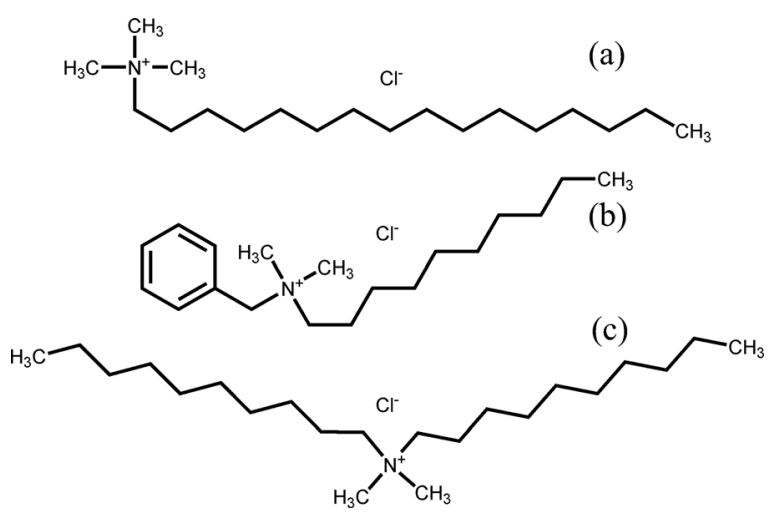

FIG. 1. Surfactants structures CTMA (a), BA (b), DDCA (c).

and schematic structures of these dyes are pictured in Figure 2. The dyes were supposed to be different regarding their nonlinear optical properties due to the strength of acceptor groups attached through azo-bond to electron accepting carbazole moiety (stronger in the case of Dye1). The samples were produced by drop casting on the glass plates cleaned according to RCA-1 recipe and afterwards were baked on the glass plates at $200{ }^{\circ}$ C. Samples contained c.a. $10 \%$ wt. of the dyes. Three groups of thin films were prepared, consisting of Dye1/DNA-DDCA, Dye1/DNA-BA, and Dye2/DNABA ([Dye1] is 4 -(9H-carbazol-3-ylazo)-3-chloro-N,N-dihydroxy-aniline, and [Dye2] is 4-(9H-carbazol-3-ylazo)-Nthiazol-2-yl-benzenesulfonamide).

\section{B. NLO measurements and analysis}

The NLO response was characterized by the optical second harmonic generation (SHG) and third harmonic generation (THG) techniques. The harmonic generation measurements were performed using diode pumped passively mode-locked $\mathrm{Nd}: \mathrm{YVO}_{4}$ laser, operating at a $1064 \mathrm{~nm}$ fundamental wavelength with a $30 \mathrm{ps}$ pulse duration and $10 \mathrm{~Hz}$ repetition rate.

The effective nonlinear susceptibilities and of thin films were obtained in air by the Maker fringes technique. ${ }^{15}$ The Maker fringes are the interference patterns obtained by the rotation of a plane parallel slab under the excitation of a laser

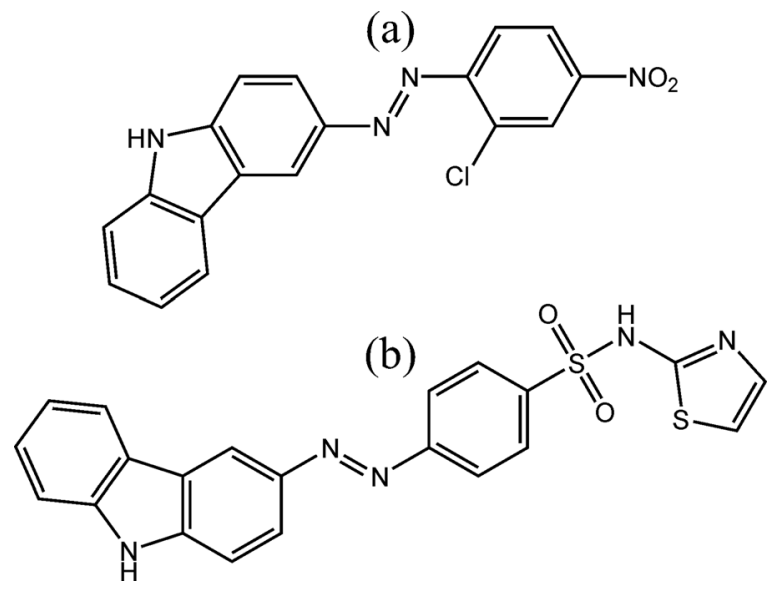

FIG. 2. Chemical structure of original dyes. (a) 4-(9H-carbazol-3-ylazo)-3chloro-N,N-dihydroxy-aniline [Dye1], (b) 4-(9H-carbazol-3-ylazo)-N-thiazol-2-yl-benzenesulfonamide [Dye2]. beam of fixed direction. The interference arises from the superposition of the free and the bound harmonic polarization waves generated in the medium by nonlinear interaction with the pump beam.

The experimental analysis of the second order susceptibilities was calculated by comparison with the SHG intensity of a standard $0.5 \mathrm{~mm}$ thick Y-cut quartz crystal plate. ${ }^{16-18}$ The simplified model of Lee et al. ${ }^{19}$ was used.

$$
\chi^{\langle 2\rangle}=\chi_{q}^{\langle 2\rangle} \frac{2}{\pi} \frac{l_{c, q}}{d}\left(\frac{I^{2 \omega}}{I^{\omega}}\right)^{1 / 2}
$$

Here, $\chi^{(2)}$ and $\chi_{q}^{(2)}$ denote second-order nonlinear susceptibilities of the studied material and quartz ${ }^{20}\left(\chi_{q}^{(2)}=1.0 \mathrm{pmV}^{-1}\right)$, respectively, $I^{2 \omega}$ and $I^{2 \omega}{ }_{q}$ are the second harmonic intensities, and $d$ is the thickness of thin film. More details are presented in our previous work. ${ }^{21}$

For THG data analysis, usually three theoretical models are used, suggested by Kubodera and Kobayashi, ${ }^{22}$ Wang et al., ${ }^{22,23}$ Reintjes, ${ }^{24}$ and Kajzar et al. ${ }^{25}$ The first relative method is based on comparison with a reference sample measured under identical conditions. It can be applied for the thin film of amorphous material the thickness of which $l$ is much smaller than the coherence length $l_{c, s}$ of the reference material. In our case, $l$ is comparable with $l_{c, s}$, therefore Reintjes and Kajzar models were chosen.

The THG intensities were calibrated with THG measurements on a high purity fused silica slab, performed under the same conditions. According to the work of Reintjes, the intensity of the third harmonic generation in a nonlinear medium is given by the following expression:

$$
I_{3 \omega}=\frac{576 \pi^{6}}{n_{3 \omega} n_{\omega}^{3} \lambda_{\omega}^{2} c^{2}}\left|\chi^{(3)}\right|^{2} I_{\omega}^{3} L^{2}\left(\sin \left(\frac{\Delta k L}{2}\right) / \frac{\Delta k L}{2}\right)^{2} .
$$

Here, $I_{\omega}$ and $I_{3 \omega}$ denote the fundamental and harmonic light intensities, respectively, and $\left|\chi^{(3)}\right|$ is the modulus of the electronic contribution of third-order nonlinear susceptibility.

$$
L=d\left(\cos \left(\arcsin \left[\sin \theta_{i} / n_{0}\right]\right)\right)^{-1}
$$

$d$ is the thickness of the material, $\theta_{i}$ is the incidence angle, and $n_{0}$ is the refractive index of the medium.

In Kajzar model for a transparent thin film, one obtains for the harmonic intensity ${ }^{26}$

$$
\begin{aligned}
I^{3 \omega}= & \frac{64 \pi^{4}}{c^{2}}\left|\frac{\chi^{\langle 3\rangle}}{\Delta \varepsilon}\right|\left(I^{\omega}\right)^{3} \mid e^{i\left(\psi_{s}^{3 \omega}+\psi_{f}^{\omega}\right)}\left[T_{1}\left(e^{i \Delta \psi_{s}}-1\right)\right. \\
& \left.+\rho e^{i \Phi} T_{2}\left(1-e^{-i \Delta \psi f}\right)\right]+\left.C_{a i r}\right|^{2} .
\end{aligned}
$$

Here, $\Delta \varepsilon$ is the dielectric constant dispersion of the medium:

$$
(\Delta \varepsilon)_{s, f}=\varepsilon_{s, f}^{\omega}-\varepsilon_{s, f}^{3 \omega}
$$

with $\Delta \varepsilon=n^{2}$. The subscripts $s$ and $f$ refer to the substrate and thin film, respectively. The phases appearing in Eq. (4) are given by 


$$
\psi_{s, f}^{\omega, 3 \omega}=\frac{3 \omega l_{s, f}}{c} n_{s, f}^{\omega, 3 \omega} \cos \theta_{s, f}^{\omega, 3 \omega}
$$

for the waves with the frequencies $\omega$ or $3 \omega$ in the medium. $\theta_{s, f}^{\omega, 3 \omega}$ are the propagation angles in the given medium. $l$ is the medium thickness and $T_{1}$ and $T_{2}$ are the factors arising from transmission and boundary conditions ${ }^{26}$

$$
\rho e^{i \Phi}=\left(\chi^{\langle 3\rangle} / \Delta \varepsilon\right)_{f} /\left(\chi^{\langle 3\rangle} / \Delta \varepsilon\right)_{s} .
$$

$\Psi_{s, f}$ is the phase of the thin film susceptibility (or difference with that of substrate if not zero), $I^{\omega}$ is the fundamental beam intensity, and the phase mismatches $\Delta \psi_{s, f}$ are given by

$$
(\Delta \psi)_{s, f}=\psi_{s, f}^{\omega}-\psi_{s, f}^{3 \omega}
$$

Here, $\psi_{s, f}^{\omega, 3 \omega}$ is given by Eq. (6).

\section{RESULTS AND DISCUSSION}

The Second Harmonic Generation and Third Harmonic Generation Maker fringes pattern measurements have been carried out in transmission mode. The intensity and the polarization of the fundamental beam (1064 nm) exciting the sample were adjusted by a half waveplate and a polarizer. The second/third harmonic light was detected by a photomultiplier, and data were recorded depending on the precisely controlled incidence angle. Before the detection, the fundamental beam was removed by KG3 filter and two interference filters (532 nm for SHG and $355 \mathrm{~nm}$ for THG) filtered off parasite room light. SHG Maker fringes measurements have been done for both $p$ and $s$ polarizations. Characteristic experimental curves are shown in Figure 3.

The SHG signal was very weak comparing to the reference quartz. The effective $\chi^{(2)}$ values have been found to be $0.011 \mathrm{pm} / \mathrm{V}$ and $0.003 \mathrm{pm} / \mathrm{V}$ for $p$ and $s$ polarization in the case of Dye1 and Dye2, respectively. THG Maker fringes measurements were taken for three samples of each group and used $s-s$ and $p-p$ polarization configurations. The high THG intensity as a function of the angle of incidence was observed in all samples and it can be seen in Figure 4.

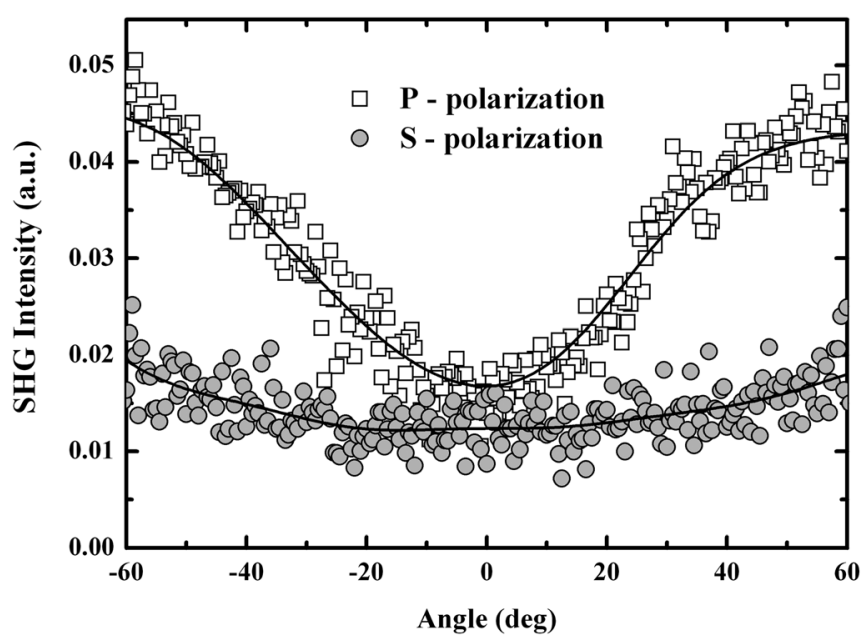

FIG. 3. An example SHG signal of Dye1/DNA-DDCA is in $p$ and $s$ polarization.

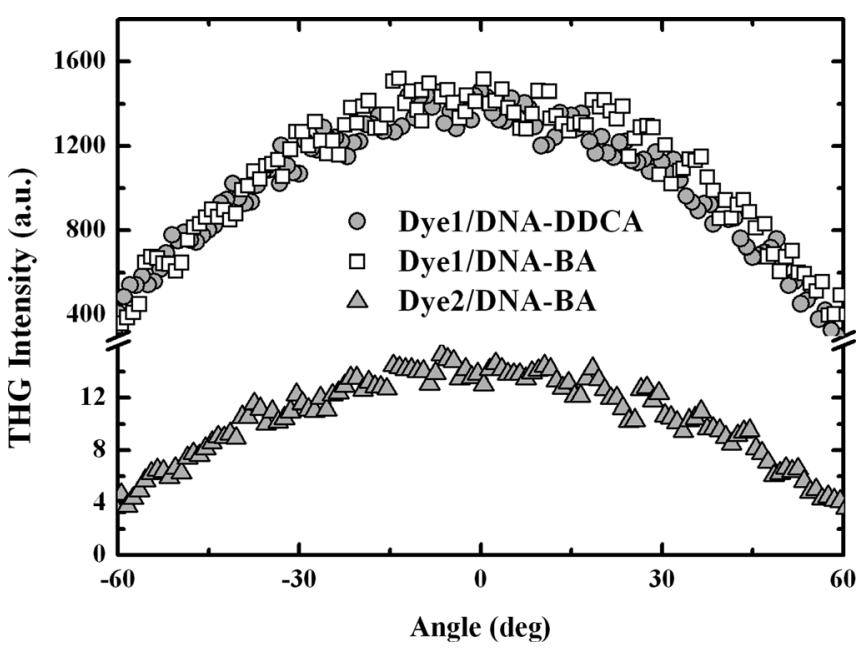

FIG. 4. An example of THG Maker fringes signal as a function of the incidence angle in s polarization.

A negligible difference has been found between the experimental data obtained for $s-s$ and $p-p$ polarizations. In order to calculate precise values of the electronic contribution of $\chi_{\text {elec }}^{(3)}$ susceptibility, ${ }^{27}$ the THG experimental data were fitted with the formulas derived by Reintjes and Kajzar.

The results of the numerical procedure are pictured by the solid lines in Figure 5.

The third order nonlinear susceptibility for both polarizations was the same within the experimental errors. The determined effective $\chi_{\text {elec }}^{(3)}$ value for two theoretical models is listed in Table I.

The $\chi^{(3)}$ values of the sample Dye2/DNA-BA are one order of magnitude higher than that of the fused silica ${ }^{28}$ used as reference in THG experiment, whereas for the samples Dye1/DNA-DDCA and Dye1/DNA-BA they are two orders of magnitude higher than in the fused silica. Moreover, these values (Dye1/DNA-DDCA and Dye1/DNA-BA) are about 5 times higher than reported in previous paper $^{29}$ for Dye1 dispersed in cured epoxy resin and more than 1.5 times higher in Ref. 30. This fact can be attributed to a better dispersion

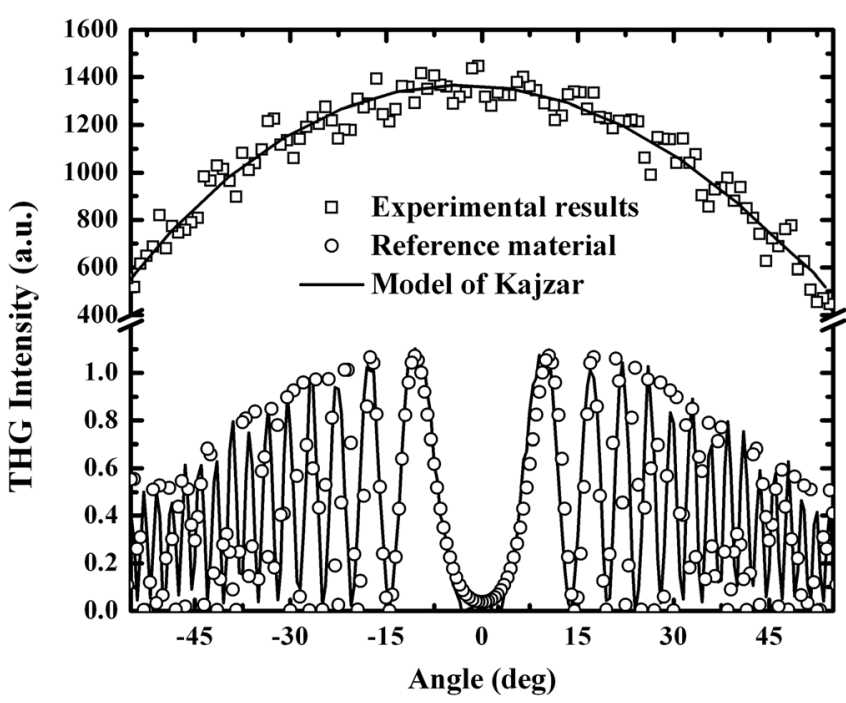

FIG. 5. An example of THG Maker fringes of Dye1/DNA-DDCA (square) in $s$ polarization and of reference material (circle) and fitted (solid line) curve. 
TABLE I. Comparison of the $\chi_{\text {elec }}^{(3)}$ values in different samples.

\begin{tabular}{lcc}
\hline \hline Model Sample & $\begin{array}{c}\text { Rentjes } \\
\chi_{\text {elec }}^{(3)}\left(\times 10^{-21} \mathrm{~m}^{2} \mathrm{~V}^{-2}\right)\end{array}$ & $\begin{array}{c}\text { Kajzar } \\
\chi_{\text {elec }}^{(3)}\left(\times 10^{-21} \mathrm{~m}^{2} \mathrm{~V}^{-2}\right)\end{array}$ \\
\hline Fused silica & & 0.2 \\
Dye1/DNA-DDCA & $17.0 \pm 1.9$ & $15.0 \pm 1.0$ \\
Dye1/DNA-BA & $19.0 \pm 1.8$ & $17.0 \pm 0.9$ \\
Dye2/DNA-BA & $1.9 \pm 0.2$ & $1.8 \pm 0.1$ \\
\hline \hline
\end{tabular}

of Dye1 molecules confined in DNA-surfactant matrix, which prevents dye molecules from aggregating. Azocarbazoles like majority of efficient NLO dyes have a strong tendency to crystallize in the matrix. Crystallites (or other aggregates) are of micrometer size (or smaller) so cannot be observed through transmission optical microscopy. Since they are not necessarily "true" crystals producing well developed x-ray diffraction peaks, their presence is most often is a subject of speculations.

In the case of Rentjes model values of cubic susceptibility are higher as compared with Kajzar model, though the last one is more precise, as it takes into account contributions both of the substrate and the air. This important condition is neglected sometimes. ${ }^{21,24}$ The effects and differences of DDCA and BA could be discussed, as this is the main topic of the paper.

\section{CONCLUSION}

Three series of different samples (Dye1/DNA-DDCA, Dye1/DNA-BA, and Dye2/DNA-BA) were prepared, and their nonlinear optical properties characterized using the second and third harmonic generation by Maker fringes technique. The second order nonlinear susceptibility was very small: $0.011 \mathrm{pm} / \mathrm{V}$ and $0.003 \mathrm{pm} / \mathrm{V}$ for $\mathrm{p}$ and s polarizations, respectively. This proves a completely statistical distribution of the dye molecules, i.e., absence of orientation induced either by the matrix or by the substrate. According to THG measurements, highest value of $\chi_{\text {elec }}^{(3)}$ was found for Dye1\DNA-BA sample and was two orders of magnitude higher than that of the fused silica, the standard reference material. Within the experimental errors, there were no differences observed in $\chi_{\text {elec }}^{(3)}$ values which might have resulted from the ionic surfactant origin.
${ }^{1}$ R. H. Horton, L. A. Moran, K. G. Scrimgeour, M. D. Perry, and J. D. Rawn, Principles of Biochemistry (Pearson Prentice Hall, New Jersey, 2006).

${ }^{2}$ H. Haranczyk, J. Czaka, P. Nowak, and J. Niziol, Acta Phys. Polon A 112, 397 (2010).

${ }^{3}$ L. L. Wang, J. Yoshida, and N. Ogata, Chem. Mater. 13, 1273 (2010).

${ }^{4}$ E. M. Heckman, J. A. Hagen, P. P. Yaney, J. G. Grote, and F. K. Hopkins, Appl. Phys. Lett 87, 211115 (2005).

${ }^{5}$ K. Tanaka and Y. Okahata, J. Am. Chem. Soc. 118, 10679 (1996).

${ }^{6}$ Y. Kawabe, L. Wang, S. Horinouchi, and N. Ogata, Adv. Mater. 12, 1281 (2000).

${ }^{7}$ O. Krupka, A. El-Ghayoury, I. Rau, B. Sahraoui, J. G. Grote, and F. Kajzar, Thin Solid Films 516, 8932 (2008).

${ }^{8}$ J. Mysliwiec, A. Miniewicz, I. Rau, O. Krupka, B. Sahraoui, F. Kajzar, and J. Grote, J. Optoelectr. Adv. Mater. 10, 2146 (2008).

${ }^{9}$ J. Mysliwiec, L. Sznitko, A. Miniewicz, F. Kajzar, and B. Sahraoui, J. Phys. D: Appl. Phys. 42, 085101 (2009).

${ }^{10}$ J. G. Grote, J. A. Hagen, J. S. Zetts, R. L. Nelson, D. E. Diggs, M. O. Stone, P. P. Yaney, E. Heckman, C. Zhang, W. H. Steier, A. K. Y. Jen, L. R. Dalton, N. Ogata, M. J. Curley, S. J. Clarson, and F. K. Hopkins, J. Phys. Chem. B 108, 8584 (2004).

${ }^{11}$ R. Czaplicki, O. Krupka, Z. Essaidi, A. El-Ghayoury, F. Kajzar, J. G. Grote, and B. Sahraoui, Opt. Express 15, 15268 (2007).

${ }^{12}$ P. Dutta and S. K. Mandal, J. Phys. D: Appl. Phys. 37, 2908 (2004).

${ }^{13}$ C. Yumusak, T. B. Singh, N. S. Sariciftci, and J. G. Grote, Appl. Phys. Lett. 95, 263304 (2009).

${ }^{14}$ J. Niziol and J. Pielichowski, Opt. Mater. 32, 673 (2010).

${ }^{15}$ P. Maker, R. Terhune, M. Nisenoff, and C. Savage, Phys. Rev. Lett. 8, 21 (1962).

${ }^{16}$ L. R. Dalton, C. Xu, A. W. Harper, R. Ghson, B. Wu, Z. Liang, R. Montgomery, and A. Jen, Nonlinear Opt. 10, 383 (1995).

${ }^{17}$ Q. W. Pan, C. S. Fang, Z. H. Qin, Q. T. Gu, X. F. Cheng, D. Xu, and J. Z. Yu, Mater. Lett. 57, 2612 (2003).

${ }^{18}$ M. Amano and T. Kaino, J. Appl. Phys. 68, 6024 (1990).

${ }^{19}$ G. J. Lee, S. W. Cha, D. J. Jeon, and S.-I. Jin, J. Korean Phys. Soc. 39, 912 (2001).

${ }^{20}$ F. Kajzar, Y. Okada-Shudo, C. Meritt, and Z. Kafafi, Synth. Met. 117, 189 (2001).

${ }^{21}$ B. Sharaoui, J. Luc, A. Meghea, R. Czaplicki, J.-L. Fillaut, and A. Migalska-Zalas, J. Opt. A: Pure Appl. Opt. 11, 024005 (2009).

${ }^{22}$ K. Kubodera and H. Kobayashi, Mol. Cryst. Liq. Cryst. 182, 103 (1990).

${ }^{23}$ X. H. Wang, D. P. West, N. B. McKeown, and T. A. King, J. Opt. Soc. Am. B 15, 1895 (1998).

${ }^{24}$ J. F. Reintjes, Nonlinear Optical Parametric Processes in Liquids and Gases (Academic, New York, 1984).

${ }^{25}$ F. Kajzar, J. Messier, and C. Rosilio, J. Appl. Phys. 60, 3040 (1986).

${ }^{26} \mathrm{~F}$. Kajzar, Characterization Techniques and Tabulations for Organic Nonlinear Optical Materials (Marcel Dekker, Inc., New York, 1998).

${ }^{27}$ W. Nie, Adv. Mater. 5, 520 (1993).

${ }^{28}$ F. Kajzar, Y. Okada-Shudo, C. Meritt, and Z. Kafafi, Synth. Int. J. Methods 117, 189 (2001).

${ }^{29}$ J. Niziol, Z. Essaidi, M. Bednarz, and B. Sahraoui, Opt. Mater. 31, 501 (2009).

${ }^{30}$ W. Bi, N. Louvain, N. Mercier, J. Luc, I. Rau, F. Kajzar, and B. Sahraoui, Adv. Mater. 20, 1013 (2008). 